\title{
Health, Disability, Psychological Well-Being, and Depressive Symptoms among Older African American Women
}

\author{
Ann W. Nguyen, University of Michigan \\ Robert Joseph Taylor, University of Michigan \\ Tina Peterson, Western Kentucky University \\ Linda M. Chatters, University of Michigan
}

\begin{abstract}
This study examines the demographic correlates of psychological well-being (i.e., happiness and life satisfaction) and mental health (i.e., depressive symptoms and serious psychological distress) among older African American women. Additionally, the relationships between self-rated physical and oral health and disability and psychological well-being and mental health are explored. Analyses are based on a nationally representative sample of older African American women from the National Survey of American Life. Results indicate that psychological well-being (i.e., life satisfaction and happiness) and mental health (i.e., depressive symptoms and serious psychological distress) are associated with specific demographic factors. In addition, self-rated health and limited mobility due to disability exerted significant influences on psychological well-being, depressive symptoms, and psychological distress. Findings are discussed in relation to prior research on demographic and health factors and their unique associations with well-being and mental status among older African American women.
\end{abstract}

\section{Introduction}

W ell-being is a complex construct that encompasses multiple domains such as physical and mental health, happiness, and life satisfaction. Well-being is a topic of enduring interest in the field of gerontology as evidenced by over sixty years of formal research and study. Current and projected growth in the size of the older population, coupled with the anticipated social, health, and economic costs, have no doubt spurred renewed interest in this issue. Finally, the current emphasis within popular culture on

Women, Gender, and Families of Color Fall 2013, Vol. 1, No. 2 pp. 105-123

(C) 2013 by the Board of Trustees of the University of Illinois 
wellness, health promotion/disease prevention, and successful aging give new impetus to issues of physical and mental well-being of older adults.

Researchers and some policy makers have long acknowledged the particularly disadvantaged circumstances of older African American women. These efforts were instrumental in documenting pervasive social and health inequalities and disparities in living and social conditions and physical and mental health status. In a groundbreaking report written almost fifty years ago, Inabel Lindsey, the founding dean of the Howard University School of Social Work, documented the high rates of poverty, poor health, inadequate housing, and poor education of African American elderly in general and older African American women in particular (National Urban League 1964). Lindsey argued that, given these circumstances, elderly black adults faced what she termed "double jeopardy," due to being old and black. In particular, she argued that older African Americans are doubly jeopardized by the confluence of social discrimination and exclusion based on both their age and race.

Without question, the most prolific researcher on elderly blacks in the 1960 and 1970 s was Jacqueline Jackson. One of her articles provided empirical evidence of the plight of older black women (Jackson 1976). In addition to a focus on the high rates of economic deprivation and health problems, the article also discussed social well-being and mental health, noting the relatively high rates of loneliness and isolation among older black women. Further efforts focused on the added impact of gender discrimination (triple jeopardy) and disability status (quadruple jeopardy) as social statuses and circumstances that further jeopardized the well-being of older black adults. The efforts of Inabel Lindsey and Jacqueline Jackson were instrumental in calling attention to the social circumstances of black elderly women and helped shape a framework that called attention to social and health disparities by race and age, as well as the role that structural forces and social discrimination play in determining the physical and mental well-being of older black adults.

Clearly, there have been tremendous gains by black women in the ensuing fifty years since the publication of Lindsey's report for the National Urban League. Although the 2008 poverty rate for black elderly (sixty-five and older) was more than double as compared to all elderly (20 percent versus 9.7 percent), it represents a significant decline from the 1968 rate of 48 percent. Similarly, compared with 1970 , when only 9 percent of black elderly were high-school graduates, in 2009, 64 percent of blacks sixtyfive and older had completed high school, and 12 percent had a bachelor's degree or higher (Administration on Aging, 2010). These data show that 
the current cohort of older African American women have higher levels of income, more years of formal education, and substantially improved health status and access to health care than previous generations. However, relative to other age and race groups (for example, non-Hispanic whites), older African American women still suffer more health problems and higher levels of poverty.

Recent data on life expectancy indicate that black women fare better than either black or white men by a margin of two to eight years, but lag behind white women by three years (Murphy et al. 2012). Profiles for chronic diseases such as diabetes indicate that rates are higher among both older persons and African Americans as compared to the general population. Specifically, 25 percent of African Americans who are between sixty-five and seventy-four years have diabetes, and 25 percent of black women over fifty-five years of age have diabetes (American Diabetes Association 2012). Rates of complications from diabetes (for example, blindness, heart disease/stroke, or kidney disease) are higher for African Americans as compared to whites (American Diabetes Association 2012). Finally, older African American women report the lowest evaluations of their health as being "excellent" or "good" in comparison to the general population (61 percent versus 74 percent) (Administration on Aging 2010).

It is important to note that, despite the high levels of economic and health problems experienced by older African American women, they remain the cornerstones of African American families. African American women are the kin keepers of their families, fulfilling important social support and caregiving roles to parents, spouses, children, grandchildren, and other relatives (Taylor, Jackson, and Chatters 1997). Finally, projected increases in the black population over sixty-five years indicate that this group will grow to 9.9 million persons in 2050 and constitute 11 percent of the older population. Given differential mortality rates, women will be represented in greater numbers in the older black population (Administration on Aging 2010). Accordingly, it is important to understand the physical and mental well-being of older black women to identify their current status and future needs.

The purpose of this study is to examine well-being-life satisfaction, happiness, serious psychological distress (SPD), and depressive symptomsamong older African American women. Specifically, this study will focus on the demographic correlates of psychological well-being and depressive symptoms, as well as the relationship between self-rated physical and oral health and psychological well-being and depressive symptoms. The majority of research on well-being and depression has focused on nonblack populations. 
This study is the first to examine the demographic profile of well-being, depressive symptoms, and SPD and their relationships with self-rated health and disability with a nationally representative sample of aging African American women. This study contributes to a small but emerging literature on wellbeing among older African Americans and is unique in that it is the first to examine self-rated oral health in relation to well-being. The literature review begins with a survey of previous research on psychological well-being (i.e., happiness, life satisfaction, depressive symptoms) and its correlates within the aging African American population. This is followed by a discussion of physical and oral health as indicators of well-being.

\section{Psychological Well-Being}

Previous research on elderly African Americans shows that life satisfaction is associated with a number of personal and social characteristics including overall health, health-promoting activities, age, marital status, education, income, socioeconomic status (SES), independence, and access to social support. Older African Americans who rated their own health favorably are more likely to be satisfied with their lives (Foster 1992; Jackson, Bacon, and Peterson 1977; Johnson, Cloyd, and Wer 1982). Poor objective health (evaluated by a health care professional) is negatively associated with life satisfactions as well; African American elders whose health was rated as poor were less satisfied with their lives than their healthier counterparts (Johnson, Cloyd, and Wer 1982). Health-promoting activities such as exercise and nutritious eating are also linked to higher life satisfaction (Foster 1992).

Age, education, income, and SES are positively associated with life satisfaction among older African Americans. Age is related to higher levels of life satisfaction (Foster 1992, Lincoln et al. 2010), as are higher levels of educational attainment, income, and SES (Foster 1992, Jackson, Bacon, and Peterson 1977). Additionally, marital status is related to life satisfaction, such that married older African Americans tend to be more satisfied with their lives than those who were separated, divorced, or widowed (Lincoln et al. 2010).

The concept of independence is an important predictor of life satisfaction and other aspects of well-being for elderly African Americans. More specifically, freedom to make independent choices and ability to function independently are related to higher levels of life satisfaction (Johnson, Cloyd, and Wer 1982). Black elderly who are disabled, who need assistance with self-care (dressing, bathing), and who have limited physical mobility may be prone to low levels of psychological well-being and high rates of depression. 
Older African Americans residing in nursing homes have a more negative outlook on life as compared to community-dwelling elders (Johnson, Cloyd, and Wer 1982). The majority of institutionalized older African Americans felt that "this was the dreariest time of their lives" and reported that they often got "down in the dumps." Features of the immediate environment and the ability to make decisions related to their welfare were positively related to elderly African Americans' life satisfaction (Johnson, Cloyd, and Wer 1982).

Turning to subjective well-being and happiness, elderly African Americans exhibit greater levels of happiness compared to elderly whites (Lincoln et al. 2010). Happiness ratings among older African Americans are associated with advanced age, being married, low levels of stress, and high health satisfaction (Chatters 1988, Lincoln et al. 2010). Subjective well-being (combining life satisfaction, happiness, and goal attainment) among older African Americans is related to health satisfaction, personal efficacy, self-esteem, marital status, and age (Tran, Wright, and Chatters 1991). Those who are satisfied with their health, have high personal efficacy and self-esteem, are married, and are of advanced age tend to report greater levels of subjective well-being than their counterparts (Tran, Wright, and Chatters 1991). Additionally, stressful life events are negatively correlated with subjective well-being (Tran, Wright, and Chatters 1991).

\section{Depressive Symptoms and Psychological Distress}

Self-reported depressive symptoms are an important aspect of mental health and well-being among older African Americans. Overall, elderly blacks have a lower prevalence rate of depressive symptoms than older whites (Gallo, Cooper-Patrick, and Lesikar 1998; Lincoln et al. 2010). Among elderly African Americans, women, persons of relatively older age, and those with lower levels of education, religiosity, and income are more likely to experience symptoms of depression (Blazer et al. 1998, Jang et al. 2005, Jang et al. 2008, Lincoln et al. 2010). Interestingly, there is a regional effect for depressive symptoms, with older African Americans living in the western U.S. being more likely to experience depressive symptoms relative to those residing in the South (Lincoln et al. 2010).

Interpersonal problems, poorer satisfaction with one's social support, functional disability, lower sense of mastery, chronic conditions, and negative life events are linked to a greater probability of experiencing depressive symptoms (Blazer et al. 1998, Jang et al. 2005, Jang et al. 2008). The effects of several of these correlates of depressive symptoms are patterned by gender 
and age. For example, a study of older adults found that, among older African American women, chronic conditions had a greater impact on depressive symptoms as compared to older African American men (Jang et al. 2008). Further, greater functional disability had a stronger influence on increasing depressive symptoms among African American women and young-old (sixty-five to seventy-four) African Americans than for men and older-old (eighty-five-plus) African Americans (Jang et al. 2008). Additionally, the relationship between religiosity and mastery as protective factors against depressive symptoms was stronger for older African American women compared with African American men (Jang et al. 2005).

Other studies indicate that older African Americans are more likely than older whites to report somatic complaints, interpersonal problems, hopelessness, problems with appetite, thoughts of death, problems with positive affect, and difficulty concentrating (Blazer et al. 1998; Gallo, Cooper-Patrick, and Lesikar 1998). Additionally, older African Americans are more likely to complain of interpersonal problems, indicate that people were unfriendly to them, and to state that they felt disliked by others (Blazer et al. 1998). On the other hand, African American elders are less likely to feel sad, lose libido, and experience sleep disturbances compared to white elders (Gallo, Cooper-Patrick, and Lesikar 1998).

Race comparative analyses of psychiatric disorders among older adults highlight important group differences. The first national study of prevalence rates of serious mental disorders among older African Americans (Ford et al. 2007) found that 5.81 percent of the sample met criteria for lifetime major depressive disorder (MDD) and 2.44 percent met criteria for twelve-month MDD. Aranda and colleagues (2012) found that, compared to non-Hispanic whites, African American elders had lower odds of having lifetime MDD. Woodward and colleagues (2012) examined DSM-IV affective disorders among a multiracial/ethnic sample (African American, black Caribbean, Latino, Asian and non-Hispanic white) of older adults. Multivariate analyses of DSM-IV affective disorders found that African American older adults were less likely than non-Hispanic whites to meet criteria for lifetime affective disorder or mood disorder. In addition, older African Americans had the lowest prevalence for MDD and dysthymia in comparison to the other groups.

Research on stress and psychological distress, two other aspects of mental health, in older African Americans shows that increasing age is related to lower probabilities of stress and psychological distress (Chatters 1988; Lincoln et al. 2010; Tran, Wright, and Chatters 1991). Health disability and being 
separated are also linked to stress in aging African Americans (Chatters 1988). Higher levels of income seem to protect against psychological distress, with older African Americans in higher income brackets being less susceptible to psychological distress than older African Americans in lower income brackets (Lincoln et al. 2010).

\section{Health}

When examining health as a dimension of well-being, previous research indicates that it is associated with education, gender, and stressful life events (Chatters 1988; Tran, Wright, and Chatters 1991). Aging African American women are more likely to have health disabilities compared to older African American men (Chatters 1988). Older African Americans with higher educational attainment experience fewer chronic health conditions but are more likely to be dissatisfied with their health than those with lower educational attainment (Chatters 1988; Tran, Wright, and Chatters 1991). Having a health disability is also associated with lower health satisfaction (Chatters 1988). Moreover, older African American women experienced more illness conditions than older African American men (Tran, Wright, and Chatters 1991). Elderly African Americans who experience more stressful life events tend to evaluate their own health poorly (Chatters 1988). Based on these findings, stressful life events appear to negatively impact many dimensions of well-being (i.e., subjective health, self-esteem, subjective well-being). Lastly, findings on oral health in the general population suggests that it is related to gender, income, education, and age (Finlayson et al. 2010). Men, those with lower income, less than high school education, and older adults are more likely to report fair or poor oral health (Finlayson et al. 2010).

\section{Focus of the Paper}

Based on prior research findings, we propose several predictions regarding the demographic and health correlates of well-being among older African American women. First, we predict that demographic correlates of wellbeing, (i.e., life satisfaction, happiness, depressive symptoms, and SPD), will converge with existing evidence regarding these relationships. Specifically, advanced age (older-old eighty-five plus) and women with more education and income will report higher levels of life satisfaction and happiness and lower levels of depressive symptoms and psychological distress. Further, good self-rated health (i.e., physical and oral) will be positively associated 
with life satisfaction and happiness and negatively associated with depressive symptoms and SPD. Disability will be negatively associated with life satisfaction and happiness and will be positively associated with depressive symptoms and SPD.

\section{Methods}

\section{Sample}

The National Survey of American Life: Coping with Stress in the 21st Century (NSAL) was collected by the Program for Research on Black Americans at the University of Michigan's Institute for Social Research. The African American sample is the core sample of the NSAL. The core sample consists of sixty-four primary sampling units (PSUs). Fifty-six of these primary areas overlap substantially with existing Survey Research Center National Sample primary areas. The remaining eight primary areas were chosen from the South in order for the sample to represent African Americans in the proportion in which they are distributed nationally. The African American sample is a nationally representative sample of households located in the forty-eight coterminous states, with at least one black adult eighteen years or over who did not identify ancestral ties in the Caribbean.

The data collection was conducted from February 2001 to June 2003. A total of 6,082 interviews were conducted with persons aged 18 or older, including 3,570 African Americans, 891 non-Hispanic whites, and 1,621 blacks of Caribbean descent. Fourteen percent of the interviews were completed over the phone, and 86 percent were administered face to face in respondents' homes. Respondents were compensated for their time. The sample for this analysis consisted of 537 African American women who were aged 55 and older.

The overall response rate was 72.3 percent. This is excellent given the difficulty and expense to conduct survey fieldwork and data collection among African Americans (especially lower-income African Americans) who are more likely to reside in major urban areas. Final response rates for the NSAL two-phase sample designs were computed using the American Association of Public Opinion Research (AAPOR) guidelines (for Response Rate 3 samples) (AAPOR 2006) (see Jackson et al. 2004 for a more detailed discussion of the NSAL sample). The NSAL data collection was approved by the University of Michigan Institutional Review Board. 


\section{Measures}

DEPENDENT VARIABLES. There are four dependent variables in this analysis (descriptive information for all dependent and independent variables are included in Table 1). Life satisfaction was measured by the following question: In general, how satisfied are you with your life as a whole these days? Would you say very satisfied (4), somewhat satisfied (3), somewhat dissatisfied (2), or very dissatisfied (1)? Overall happiness was assessed by the following question: Taking all things together, how would you say things are these days? Would you say you are very happy (4), pretty happy (3), or not too happy these days (2)? A few respondents volunteered that they were "not happy at all" (1).

Depressive symptoms were assessed using the twelve-item version of the Center for Epidemiological Studies-Depression scale (CES-D) (Radloff 1977). This abbreviated CES-D has been found to have acceptable reliability and a similar factor structure, compared with the original version. Item responses are coded 1 (hardly ever) to 3 (most of the time). These twelve items measure the extent to which, in the past thirty days, respondents had trouble keeping their mind on tasks, enjoyed life, had crying spells, could not get going, felt depressed, hopeful, restless, happy, as good as other people, that everything was an effort, that people were unfriendly, and that people dislike them. Positive valence items were reverse coded and summed. The mean was computed across the twelve items, resulting in a continuous measure of depressive symptoms; high scores indicate a greater number of depressive symptoms (Cronbach's alpha $=0.79$ ).

Serious psychological distress (SPD) was measured by the K6 that is a six-item scale designed to assess nonspecific psychological distress including symptoms of depression and anxiety in the past thirty days (Kessler et al. 2002, 2003). Specifically, the K6 includes items designed to identify individuals: 1) with a high likelihood of having a diagnosable mental illness and associated limitations and 2) who have mental health problems severe enough to cause moderate to serious impairment in social and occupational functioning and to require treatment. Each item was measured on a five-point Likert scale ranging from o (none of the time) to 4 (all of the time). Positive valence items were reverse coded, and summed scores ranged from o to 22, with higher scores reflecting higher levels of psychological distress (Cronbach's alpha $=0.83$ ).

INDEPENDENT VARIABLES. Several demographic factors (i.e., age, marital status, region, education, family income), two measures of disability, and two measures of self-rated health were included as independent 
variables. Missing data for family income and education were imputed using an iterative regression-based multiple imputation approach incorporating information about age, sex, region, race, employment status, marital status, home ownership, and nativity of household residents. Income is coded in dollars and, for the multivariate analysis only, has been divided by 5,000 in order to increase effect sizes and provide a better understanding of the net impact of income on the dependent variables.

There are two variables that measure disability in the areas of general mobility and self-care. Both measures used a modified version of the World Health Organization Disability Assessment Schedule (WHO-DASII). For selfcare, respondents were asked about their difficulties with washing their whole body, getting dressed, and staying by themselves for a few days. For mobility, respondents were asked about their difficulties with standing for long periods, moving around inside their homes, or walking for a long distance (half a mile). Both mobility and self-care were assessed for the past thirty days. For both self-care and mobility, items assessed the number of days of impairment, weighted by self-assessed difficulty in performing these activities. Both measures were transformed into a scale ranging from $100=$ completely impaired to $\mathrm{o}=$ no impairment. Two measures of self-rated health were also included in this analysis. Self-rated physical health was measured by respondents' rating of their overall physical health at the present time $(1=$ poor to $5=$ excellent $)$. Self-rated oral health was measured by respondent's rating of their overall oral health at the present time $(1=$ poor to $5=$ excellent $)$.

\section{Analysis Strategy}

All analyses were conducted using SAS 9.13, which uses the Taylor expansion approximation technique for calculating the complex design-based estimates of variance. All of the analyses utilize analytic weights. Statistical analyses accounted for the complex multistage clustered design of the NSAL sample, unequal probabilities of selection, nonresponse, and poststratification to calculate weighted, nationally representative population estimates and standard errors.

\section{Results}

The mean age of respondents is 66.6 years, and the mean family income is $\$ 28,412$. On average, respondents report some high school in terms of educational attainment level. More than half of all respondents reside in the 
Table 1. Demographic Characteristics of the Sample and Distribution of Study Variables

\begin{tabular}{|c|c|c|c|c|c|}
\hline & $\%$ & $\mathrm{~N}$ & Mean & S.D. & Range \\
\hline Life Satisfaction & & 537 & 3.36 & 0.61 & $4-1$ \\
\hline Happiness & & 530 & 3.28 & 0.53 & $4-1$ \\
\hline Depressive Symptoms (CES-D) & & 496 & 5.21 & 4.44 & $33-($ \\
\hline Serious Psychological Distress (K6) & & 499 & 2.72 & 2.99 & $18-($ \\
\hline Age & & 537 & 66.64 & 6.94 & $93-5$ \\
\hline Family Income & & 537 & 28411.71 & 25222.51 & $450000-$ \\
\hline Education & & 537 & 11.62 & 2.70 & $17-c$ \\
\hline \multicolumn{6}{|l|}{ Marital Status } \\
\hline Married & 29.11 & 119 & & & \\
\hline Divorced & 5.49 & 31 & & & \\
\hline Widowed & 14.71 & 92 & & & \\
\hline Separated & 44.85 & 254 & & & \\
\hline Never Married & 5.83 & 35 & & & \\
\hline \multicolumn{6}{|l|}{ Region } \\
\hline Northeast & 16.74 & 69 & & & \\
\hline North Central & 19.80 & 98 & & & \\
\hline South & 54.67 & 341 & & & \\
\hline West & 8.79 & 29 & & & \\
\hline Self-Care & & 506 & 1.19 & 6.14 & $100-($ \\
\hline Mobility & & 506 & 6.80 & 14.16 & $91.67-($ \\
\hline Self-Rated Physical Health & & 506 & 3.04 & 0.89 & $5-1$ \\
\hline Self-Rated Oral Health & & 506 & 2.80 & 0.94 & $5-1$ \\
\hline
\end{tabular}

Percents and $\mathrm{N}$ are presented for categorical variables and Means and Standard Deviations are presented for continuous variables. Percentages are weighted and frequencies are un-weighted.

South, and a large proportion report being either separated (44.9 percent) or married (29.1 percent). Overall, respondents indicate relatively high life satisfaction and happiness scores and relatively low depressive symptoms and SPD scores. Very few older women report problems with self-care and mobility due to disability, and they rate their physical and oral health as fair.

The results of the regression analysis for life satisfaction are presented in Table 2. Age, marital status, and self-rated physical health were significantly associated with life satisfaction. Relatively older women had higher levels of life satisfaction than their younger counterparts. Married women had higher levels of life satisfaction than their divorced and widowed counterparts. Separated and never married respondents also had lower levels of life satisfaction than their married counterparts, but their coefficients did not attain statistical significance. Women with higher levels of self-rated health also have higher levels of life satisfaction. Self-rated oral health and life satisfaction bordered significance $(\mathrm{p}=.059)$. 
Table 2. Weighted linear regression analyses for measures of psychological well-being for older African American women.

\begin{tabular}{lcccc}
\hline & \multicolumn{2}{c}{ Life Satisfaction } & \multicolumn{2}{c}{ Happiness } \\
\cline { 2 - 5 } & $\mathrm{B}$ & S. E. & $\mathrm{B}$ & S. E. \\
\hline Age & 0.01 & $0.00^{* *}$ & 0.01 & $0.00^{* * *}$ \\
Income & -0.01 & 0.01 & -0.01 & $0.00^{*}$ \\
Education & 0.01 & 0.01 & 0.00 & 0.01 \\
Marital Status & & & & \\
$\quad$ Divorced & -0.29 & $0.14^{*}$ & -0.26 & 0.17 \\
$\quad$ Widowed & -0.22 & $0.08^{*}$ & -0.11 & 0.10 \\
$\quad$ Separated & -0.12 & 0.07 & -0.04 & 0.08 \\
$\quad$ Never Married & -0.41 & 0.20 & -0.18 & 0.13 \\
Region & & & & \\
$\quad$ Northeast & -0.18 & 0.12 & -0.21 & 0.14 \\
$\quad$ North Central & -0.22 & 0.14 & -0.24 & $0.09^{*}$ \\
$\quad$ West & 0.17 & 0.16 & -0.06 & 0.14 \\
Self-Care & 0.00 & 0.00 & 0.00 & 0.00 \\
Mobility & -0.00 & 0.00 & -0.00 & $0.00^{* *}$ \\
Self-Rated Physical Health & 0.10 & $0.03^{* * *}$ & 0.06 & 0.05 \\
Self-Rated Oral Health & 0.07 & 0.04 & 0.05 & 0.03 \\
Constant & 2.05 & $0.33^{* * *}$ & 2.28 & $0.25^{* * *}$ \\
N & 505 & & 504 & \\
F & $22.96^{* * *}$ & & $18.95^{* * *}$ & \\
R & 0.13 & & 0.12 & \\
\hline
\end{tabular}

Note: Several predictors are represented by dummy variables:, marital status: Married $=0$ and region: South $=0$. Income is coded in dollars and has been divided by 5,000 in order to increase effect sizes and provide a better understanding of the net impact of income. All of the coefficients are unstandardized. ${ }^{*} \mathrm{p}<.05 ;{ }^{* *} \mathrm{p}<.01 ;{ }^{* *} \mathrm{p}<.001$

Age, region, income, and mobility were all significantly associated with happiness (Table 2). Older women had higher levels of happiness than their younger counterparts and southerners reported higher levels of happiness than respondents who resided in the north-central region. Respondents with higher levels of income reported lower levels of happiness. Lastly, older women with higher levels of mobility-related disability had lower levels of happiness.

Table 3 presents the results of the regression analysis of depressive symptoms and serious psychological distress. Age, region, education, and self-rated physical health were all significantly related to depressive symptoms. Relatively older women and those with higher levels of education had fewer depressive symptoms than their counterparts. Respondents who resided in the West had more depressive symptoms than those who resided in the South, while those with higher levels of self-rated physical health had fewer depressive symptoms.

Age, education, self-rated physical health, self-rated oral health, and mobility were all significantly associated with psychological distress (Table 
Table 3. Weighted linear regression analyses for measures of psychological distress for older African American women.

\begin{tabular}{lcccc}
\hline & \multicolumn{2}{c}{$\begin{array}{c}\text { Depressive } \\
\text { Symptoms (CES-D) }\end{array}$} & \multicolumn{2}{c}{ Serious } \\
& \multicolumn{1}{c}{$\mathrm{B}$} & S. E. & B & S. E. \\
\cline { 2 - 5 } & -0.10 & $0.04^{*}$ & -0.08 & $0.02^{* *}$ \\
\hline Age & -0.07 & 0.07 & -0.05 & 0.05 \\
Income & -0.33 & $0.09^{* *}$ & -0.25 & $0.08^{* *}$ \\
Education & & & & \\
Marital Status & -0.87 & 1.25 & -1.31 & 0.80 \\
$\quad$ Divorced & -0.04 & 0.94 & -0.63 & 0.63 \\
Widowed & 0.27 & 0.81 & -0.24 & 0.53 \\
$\quad$ Separated & 1.86 & 1.17 & 1.23 & 0.81 \\
$\quad$ Never Married & & & & \\
Region & 0.43 & 0.86 & 0.14 & 0.56 \\
$\quad$ Northeast & -0.01 & 0.52 & -0.03 & 0.37 \\
$\quad$ North Central & 1.71 & $0.42^{* * *}$ & 0.42 & 0.50 \\
$\quad$ West & 0.01 & 0.04 & -0.01 & 0.02 \\
Self-Care & 0.03 & 0.02 & 0.03 & $0.01^{* *}$ \\
Mobility & -0.83 & $0.33^{*}$ & -0.44 & $0.22^{*}$ \\
Self-Rated Physical Health & -0.51 & 0.28 & -0.62 & $0.14^{* * *}$ \\
Self-Rated Oral Health & 19.14 & $3.01^{* * *}$ & 14.38 & $2.10^{* * *}$ \\
Constant & 496 & & 499 & \\
N & 14.81 & & 12.45 & \\
F & $0.16^{* * *}$ & & $0.21^{* * *}$ & \\
R & & & & \\
\hline
\end{tabular}

Note: Several predictors are represented by dummy variables:, marital status: Married $=0$ and region: South $=0$. Income is coded in dollars and has been divided by 5,000 in order to increase effect sizes and provide a better understanding of the net impact of income. All of the coefficients are unstandardized. ${ }^{*} \mathrm{p}<.05 ;{ }^{* *} \mathrm{p}<.01 ;{ }^{* *} \mathrm{p}<.001$

3). Older women and those with more years of formal education had lower levels of serious psychological distress. Respondents with higher levels of self-rated physical health and self-rated oral health had lower levels of psychological distress. Lastly, older African American women with higher levels of mobility-related disability had higher levels of psychological distress.

\section{Discussion}

This study of demographic and health correlates of psychological well-being and psychological distress among a nationally representative sample of older African American women found both similarities and divergences from previous work. Overall, older women had relatively high levels of well-being and mental health, displaying high levels of life satisfaction and happiness and minimal depressive symptoms and serious psychological distress. For 
the most part, our findings are consistent with extant research on well-being and mental health among older African Americans (Chatters 1988; Aranda et al. 2012; Ford et al. 2007; Woodward et al. 2012; Tran, Wright, and Chatters 1991). As anticipated, age was consistently associated with all four dependent variables. Within this sample of African American women, those who were relatively older were both more likely to be satisfied with their lives and happy and less likely to report depressive symptoms and SPD than their younger age counterparts. Positive age findings for well-being may be attributed to healthy survivor effect-a selection process whereby healthy individuals are selectively retained within a population, while those who are less healthy are removed. In essence, older African American women who have serious mental health problems (for example, depressive symptoms, SPD) are less likely to advance to old age (Strauss et al. 2004), whereas those without psychological difficulties are more likely to reach old age. Thus, the oldest women in this sample may be more well-adjusted and exhibit greater levels of well-being than younger elders.

Education was negatively associated with depressive symptoms and SPD, with respondents with higher levels of education reporting lower levels of both depressive symptoms and SPD. These findings are similar to what is known about the general elderly African American population and suggest that education may have a protective role in reducing overall risk for depressive symptoms and psychological distress. Education effects on depressive symptoms and SPD may reflect both the life advantages gained with higher levels of schooling (jobs, occupation, housing) and greater cognitive resources (for example, information, strategies) that are important for a range of health outcomes (Lynch and Kaplan 2000). Education was unrelated to life satisfaction and happiness (Chatters 1988) suggesting that education is only a reliable predictor of depressive symptoms and psychological distress, but not psychological well-being. Income was unrelated to depressive symptoms and SPD and significantly and negatively associated with happiness only. Previous findings for older African Americans are mixed, indicating either no relationship between income and psychological well-being (for example, Chatters 1988, Lincoln et al. 2010) or positive income effects for well-being (for example, Foster 1992; Jackson, Bacon, and Peterson 1977). Thus, the negative association between income and happiness in this study is unexpected and warrants further study.

Married respondents were more satisfied with their lives than divorced and widowed respondents, which confirms previous findings that married African American elders have higher levels of psychological well-being than 
their unmarried counterparts (Chatters 1988; Lincoln et al. 2010; Tran, Wright, and Chatters 1991). Although previous work on older African Americans (Chatters 1988) indicated that marriage was associated with greater happiness and lower stress, in this sample of older women, being married had no specific benefit in terms of happiness, depressive symptoms, or SPD.

Regional differences in happiness indicate that older African American women in the South had higher levels of happiness relative to women living in the north-central region of the country. Further, similar to Lincoln and colleagues' (2010) findings, older women in the West reported more depressive symptoms than southern residents. One interpretation of these findings focuses on regional differences in religiosity. Extensive research documents the beneficial effect of religiosity on well-being and mental health (Chatters et al. 2008; Koenig, King and Carson 2012; Levin, Chatters, and Taylor 1995; Lincoln and Chatters 2003; Schieman et al. 2006). Further, African Americans in the south report the highest levels of religiosity, while those residing in the West have the lowest (Taylor, Chatters, and Levin 2004). Consequently, the noted southern advantage for happiness and fewer depressive symptoms may, in fact, have its origin in regional differences in religiosity.

Self-rated physical health was predictive of depressive symptoms, SPD, and life satisfaction. Positive ratings of physical health were associated with fewer depressive symptoms, lower levels of SPD, and higher levels of life satisfaction. Prior studies have indicated relationships between self-rated health and psychological well-being (Chatters 1988; Tran, Wright, and Chatters 1991) and psychological distress. Limited mobility due to disability was associated with higher levels of SPD and lower happiness ratings. Mobility was also significantly associated with depressive symptoms and life satisfaction but failed to reach significance when self-rated health was included in the model. This suggests that self-rated health exerts a greater influence on depressive symptoms and life satisfaction than mobility. Disability related to self-care activities (for example, bathing, dressing) was not related to any of the dependent measures.

Finally, self-rated oral health had more limited effects than physical health in this analysis. However, consistent with Finlayson and colleagues' (2010) finding that depression is positively correlated with fair to poor oral health, older women in this sample who rated their oral health unfavorably reported higher levels of SPD. Oral health is a particularly important issue that has been understudied in connection to well-being, psychological distress, and depressive symptoms. Prominent characteristics of poor oral health-including, pain, difficulties eating, and being self-conscious about 
appearance-have significant impacts on how satisfied people are with their oral health. In addition, any of these problems, if severe or chronic, could negatively impact well-being and increase depressive symptoms. Oral health is also critical because dental care it is not covered or inadequately covered in many health insurance plans. In other words, lower-income populations, such as the African American and aging populations, tend to be affected disproportionately by this and are less likely to seek professional care for oral health issues due to lack of dental insurance coverage. Consequently, the impact of oral health on well-being and depression among older adults is an issue that warrants further study.

Despite the strengths of the present investigation, interpretations of these findings should be examined within the context of limitations of the study. All measures in this study were self-reported, which are subjected to recall and social desirability biases. Information on depressive symptoms and SPD were reported for the past month prior to the interview. As such, there is no information as to whether respondents had experienced prior episodes of depressive symptoms and SPD, if they were persistent over time, and their exact causal relation to physical health and well-being-questions that are appropriate for prospective study designs. Respondents were non-institutionalized, community-dwelling older African American women, so that study findings are generalizable to this population. Older women who were institutionalized or who were physically compromised and unable to participate in the interview were excluded.

Despite these limitations, the present analysis demonstrates important demographic differences in psychological well-being and psychological distress among older African American women. One of the strengths of this analysis is the ability to examine specific measures of mental health status (i.e., depressive symptoms and SPD), as well as more general assessments of well-being (i.e., happiness and life satisfaction). The use of multiple measures permits a more in-depth understanding of their distinctiveness to one another and of how demographic factors are differentially associated with well-being and mental health. This study also makes a unique contribution in examining the relationships between self-rated physical and oral health and mental health and general well-being. Findings for physical health confirm prior work on the important connections between physical and mental health and well-being. Prior to this study, self-rated oral health has not been examined in relation to older African American women's psychological distress and depressive symptoms. Findings for disability-related mobility restrictions indicated its importance for SPD and happiness ratings, independent 
of self-rated physical health. Accordingly, both physical health and mobility should be assessed to understand better their unique contributions to the mental health and well-being of older African American women.

In sum, this study underscores the importance of focused research on the many minority groups within the United States and the nuanced understanding that is gained from this research. This in-depth examination provides a fuller understanding of how older African American women characterize their mental health and overall life circumstances and identifies how particular demographic and health factors may confer specific risks (for example, being unmarried) and protections (for example, advanced age, education) on their mental status and well-being.

\section{References}

Administration on Aging. "A Statistical Profile of Black Older Americans Aged 65+." Administration on Aging, U.S. Department of Health and Human Services. 2010. Retrieved from: http://www.aoa.gov/aoaroot/Press_Room/Products_Materials/pdf/Stat_ Profile_Black_Aged_65.pdf. Accessed September 10, 2012.

American Association for Public Opinion Research (AAPOR). Standard Definitions: Final Dispositions of Case Codes and Outcome Rates for Surveys. 4th ed. Lenexa, KS: AAPOR, 2006.

American Diabetes Association. "African Americans and Complications." American Diabetes Association. 2012. Retrieved from: http://www.diabetes.org/living-with-diabetes/ complications/african-americans-and-complications.html. Accessed September 10, 2012.

Aranda, María P., David H. Chae, Karen D. Lincoln, Robert Joseph Taylor, Amanda Toler Woodward, and Linda M. Chatters. “Demographic Correlates of DSM-IV Major Depressive Disorder among Oder African Americans, Black Caribbeans, and Non-Hispanic Whites: Results from the National Survey of American Life." International Journal of Geriatric Psychiatry 27 (2012): 940-47.

Blazer, Dan G., Lawrence R. Landerman, Judith C. Hays, Eleanor M. Simonsick, and W. B. Saunders. "Symptoms of Depression among Community-dwelling Elderly African-American and White Older Adults." Psychological Medicine 28 no. 6 (1998): 1311-20.

Chatters, Linda M. "Subjective Well-being Evaluations among Older Black Americans." Psychology and Aging 3 no. 2 (1988): 184-90.

Chatters, Linda M., Robert Joseph Taylor, James S. Jackson, and Karen D. Lincoln. "Religious Coping among African Americans, Caribbean Blacks and Non-Hispanic Whites." Journal of Community Psychology 36, no. 3 (1988): 371-86.

Chatters, Linda M., Kai Mckeever Bullard, Robert Joseph Taylor, Amanda T. Woodward, Harold W. Neighbors, and James S. Jackson. "Religious Participation and DSM-IV Disorders among Older African Americans: Findings from the National Survey of American Life (NSAL)." American Journal of Geriatric Psychiatry 16 (2008): 957-65.

Finlayson, Tracy L., David R. Williams, Kristine Siefert, James S. Jackson, and Ruth Nowjack- 
Raymer. "Oral Health Disparities and Psychosocial Correlates of Self-rated Oral Health in the National Survey of American Life." American Journal of Public Health 100 (2010): S246-S255.

Ford, Briggett C., Kai McKeever Bullard, Robert Joseph Taylor, Amanda K. Toler, Harold W. Neighbors, and James S. Jackson. "Lifetime and 12-Month Prevalence of Diagnostic and Statistical Manual of Mental Disorders, Fourth Edition Disorders among Older African Americans: Findings From the National Survey of American Life." American Journal of Geriatric Psychiatry 15, no. 8 (2007): 652-59.

Foster, Miriam F. “Health Promotion and Life Satisfaction in Elderly Black Adults." Western Journal of Nursing Research 14, no. 4 (1992): 444-63.

Gallo, Joseph J., Lisa Cooper-Patrick, and Sandra Lesikar. "Depressive Symptoms of Whites and African Americans Aged 60 Years and Older." Journals of Gerontology Series B: Psychological Sciences and Social Sciences 53, no. 5 (1998): P277-P286.

Jackson, Jacquelyne J. “The Plight of Older Black Women in the United States." Black Scholar 7, no. 7 (1976): 47-55.

Jackson, James S., John D. Bacon, and John Peterson. "Life Satisfaction among Black Urban Elderly." International Journal of Aging and Human Development 8, no. 2 (1977): 169-79.

Jackson, James S., Myriam Torres, Cleopatra H. Caldwell, Harold W. Neighbors, Randolph M. Nesse, Robert Joseph Taylor, Steven J. Trierweiler, and David R. Williams. "The National Survey of American Life: A Study of Racial, Ethnic And Cultural Influences on Mental Disorders and Mental Health." International Journal of Methods in Psychiatric Research 13, no. 4 (2004): 196-207.

Jang, Yuri, Amy R. Borenstein, David A. Chiriboga, and James A. Mortimer. "Depressive Symptoms among African American and White Older Adults." Journals of Gerontology Series B: Psychological Sciences and Social Sciences 60, no. 6 (2005): P313-P319.

Jang, Yuri, David A. Chiriboga, Giyeon Kim, and Karon Phillips. "Depressive Symptoms in Four Racial and Ethnic Groups: The Survey of Older Floridians (SOF)." Research on Aging 30, no. 4 (2008): 488-502.

Johnson, Freddie, Cynthia Cloyd, and Jo Ann Wer. "Life Satisfaction of Poor Urban Black Aged." Advances in Nursing Science 4, no. 3 (1982): 27-34.

Kessler, Ronald C., G. Andres, Lisa J. Colpe, Eva Hiripi, D. K. Mroczek, Sharon T. Normand, Ellen E. Walters, and Alan M. Zaslavsky. "Short Screening Scales to Monitor Population Prevalences and Trends in Non-Specific Psychological Distress. Psychological Medicine 32 (2002): 959-76.

Kessler, R. C., Peggy R. Barker, Lisa J. Colpe, Joan F. Epstein, Joseph C. Gfroerer, Eva Hiripi, et al. "Screening for Serious Mental Illness in the General Population." Archives of General Psychiatry 60 (2003): 184-89.

Koenig, Harold G., Dana King, and Verna B. Carson. Handbook of Religion and Health. 2d ed. New York: Oxford University Press, 2012.

Levin, Jeffrey S., Linda M. Chatters, and Robert J. Taylor. "Religious Effects on Health Status and Life Satisfaction among Black Americans." Journals of Gerontology Series B: Psychological Sciences and Social Sciences 50, no. 3 (1995): S154-S163.

Lincoln, Karen D., and Linda M. Chatters. "Keeping the Faith: Religion, Stress, and Psychological Well-Being among African American Women." In In and Out of Our Right Minds: African American Women and Mental Health, edited by Diane R. Brown and Verna M. Keith, 223-41. New York: Columbia University Press, 2003. 
Lincoln, Karen D., Robert J. Taylor, David H. Chae, and Linda M. Chatters. "Demographic Correlates of Psychological Well-being and Distress among Older African Americans and Caribbean Black Adults." Best Practices in Mental Health 6, no. 1 (2010): 103-26.

Lynch, John, and George Kaplan. "Socioeconomic Position" In Social Epidemiology, edited by Lisa F. Berkman and Ichiro Kawachi, 13-35. New York: Oxford University Press, 2000.

Murphy, Sherry L., Jiaquan Xu, and Kenneth D. Kochanek. "Deaths: Preliminary Data for 2010." National Vital Statistics Reports 60, no. 4 (2012): 1-51.

National Urban League. Double Jeopardy: The Older Negro in America Today. New York: National Urban League, 1964.

Radloff, Lenore S. “The CES-D Scale: A Self-Reported Depression Scale for Research in the General Population.” Applied Psychological Measurement 1 (1977): 385-401.

Schieman, Scott, Tetyana Pudrovska, Leonard I. Pearlin, Christopher G. Ellison. “The Sense of Divine Control and Psychological Distress: Variations across Race and Socioeconomic Status. Journal for the Scientific Study of Religion 45 (2006): 529-49.

Strauss, David, Kelly Ojdana, Robert Shavelle, and Lewis Rosenbloom. "Decline in Function and Life Expectancy of Older Persons with Cerebral Palsy." NeuroRehabilitation 19, no. 1 (2004): 69-78.

Taylor, Robert Joseph, Linda M. Chatters, and Jeff Levin. Religion in the Lives of African Americans: Social, Psychological, and Health Perspectives. Thousand Oaks, CA: Sage Publications, 2004 .

Taylor, Robert Joseph, James S. Jackson, and Linda M. Chatters, eds. Family Life in Black America. Thousand Oaks, CA: Sage Publications, 1997.

Tran, T. V., Roosevelt Wright, and Linda M. Chatters. "Health, Stress, Psychological Resources, and Subjective Well-being among Older Blacks." Psychology and Aging 6, no. 1 (1991): 100-108.

Woodward, Amanda Toler, Robert Joseph Taylor, Kai McKeever Bullard, Maria P. Aranda, Karen D. Lincoln, and Linda M. Chatters. "Prevalence of Lifetime DSM-IV Affective Disorders among Older African Americans, Black Caribbeans, Latinos, Asians and NonHispanic White People." International Journal of Geriatric Psychiatry 27 (2012): 816-27. 